\title{
Comparison of Polysaccharides Produced by Myxococcus Strains
}

\author{
By I. W. SUTHERLAND AND SUSAN THOMSON \\ Department of Microbiology, University of Edinburgh, Edinburgh $\mathrm{EH}_{9}{ }_{3} \mathrm{JG}$
}

(Received 30 December 1974; revised 12 February 1975)

\begin{abstract}
SUMMARY
Exopolysaccharides were prepared from cultures of four Myxococcus strains grown on solid and in liquid media, and also from the fruiting bodies. Lipopolysaccharides could be extracted with aqueous phenol from the vegetative bacteria, but were absent from microcysts. Mannose and D-glucose were present in all the exopolysaccharides and three of the lipopolysaccharides examined. Other monosaccharides identified in the exopolysaccharides were D-galactose, $\mathrm{N}$-acetylglucosamine and $N$-acetylgalactosamine. The composition of the lipopolysaccharides was more complex than that of the exopolysaccharides and, in addition to the neutral hexoses and amino sugars, rhamnose was identified in two preparations and ribose in another. No lipopolysaccharide preparations contained $O$-methyl xylose or heptose.

The polysaccharides secreted by the bacillary forms grown on solid or in liquid media closely resembled the polysaccharides isolated from the fruiting bodies, in which they provided a matrix surrounding the microcysts. Each pair of polysaccharides contained the same monosaccharides, although in slightly different proportions. Differences were found in preparations from different strains. These results suggest that in the developmental cycle of the genus Myxococcus, considerable use is made of pre-existing enzyme systems to synthesize the precursors necessary for polysaccharide synthesis. Any specific difference between the polysaccharide produced by the bacilli and that surrounding the microcysts may lie in the fine structure, rather than in the individual components.
\end{abstract}

\section{INTRODUCTION}

Genera of the Myxobacteria characteristically produce slime during growth and it is of interest to know whether there is any resemblance to slime moulds in the production of various polysaccharides during different phases of growth. The vegetative cells of Myxobacteria resemble other Gram-negative species in containing lipopolysaccharides in their walls which are extractable with hot aqueous phenol (Sutherland \& Smith, 1973) and mucopeptide (White, Dworkin \& Tipper, 1968). Lipopolysaccharides from the fruiting species of Myxobacteria which were examined showed a gross similarity to the corresponding polymers from other Gram-negative bacteria, but some preparations also contained the sugar 3-O-methyl-D-xylose (Weckesser et al. 197I; Sutherland \& Smith, 1973). The composition of lipopolysaccharide from Myxococcus fulvus has been examined and compared with preparations from other fruiting and non-fruiting Myxobacteria (Rosenfelder, Lüderitz \& Westphal, 1974). The mucopeptide of Myxococcus xanthus differed between the vegetative and cyst forms (White et al. 1968). One strain of $M$. xanthus yielded a glucose-containing polymer associated with the mucopeptide (Johnson \& White, 1972). Glucose was present in larger quantities in vegetative cells than in microcysts. 
Little work has been reported on extracellular polysaccharides, although White et al. (1968) considered that galactosamine found in increasing amounts during microcyst formation might be derived from capsular material. Cytophaga (previously Chondrococcus) columnaris was shown to secrete a slime that contained galactosamine (Johnson \& Chilton, 1966). The production of extracellular polysaccharide, as anthrone-reactive material, was followed in cultures of Myxococcus virescens (Haskå \& Ståhl, 1971). Although the amount increased almost linearly with time during the exponential phase of growth, no attempt was made to determine the composition of the material.

The genus Myxococcus provides an excellent system for the study of polysaccharide production during the different stages of growth and differentiation because vegetative bacteria on solid surfaces excrete a large quantity of slime which is presumed to be polysaccharide. The fruiting body in this genus consists of a balloon-shaped collection of microcysts surrounded by slime (Dworkin, 1972). The present study aimed at determining the nature of the cell wall and extracellular polysaccharides produced by several Myxococcus isolates under different growth conditions and in the alternative cell forms, with a view to assessing their role in development.

\section{METHODS}

Bacterial strains. Two strains of Myxococcus species (strains E and A) were isolated from local soil, while a third isolate (strain $\mathrm{M}$ ) was found as the predominant microbial type on a sample of seaweed collected near the high water mark. All three strains grew well on cell agar (a suspension of $0.1 \%, \mathrm{w} / \mathrm{v}$, Klebsiella aerogenes in tap water, solidified with $\mathrm{I} \%$, w/v, agar) at $30{ }^{\circ} \mathrm{C}$, on Cro agar (Reichenbach \& Dworkin, I969), and in Cio liquid medium in shake-flasks at $30{ }^{\circ} \mathrm{C}$. Growth in liquid medium was in the form of clumps that increased in size during incubation. Isolate $M$ also grew slowly in similar media prepared with a seawater base. All three strains possessed the major characteristics of Myxococcus species in terms of cell size and shape, and readily produced fruiting bodies on suitable media. Slight differences were detectable in the pigmentation of the cultures. Myxococcus xanthus strain MFB, kindly provided by Professor M. Dworkin, Department of Microbiology, University of Minnesota, U.S.A., was the only one of the four strains tested that gave dispersed growth in liquid media.

Polysaccharide production and isolation. Lipopolysaccharides were prepared as described by Sutherland \& Smith (1973) from bacteria grown in Cro medium, lyophilized and extracted with chloroform-methanol $(2: \mathrm{I}, \mathrm{v} / \mathrm{v})$. The product was purified by ultracentrifugation at I00000 $\mathrm{g}$ for $4 \mathrm{~h}$ and lipid A was removed by hydrolysis in I\% $\% / \mathrm{v})$ acetic acid for $\mathrm{I} \mathrm{h}$ at I00 ${ }^{\circ} \mathrm{C}$. The product was dialysed overnight against distilled water, freed from lipid by low-speed centrifugation, and lyophilized.

Polysaccharides from bacteria grown on solid medium, Cio agar, were obtained after 3 to 4 days of incubation at $30^{\circ} \mathrm{C}$. To avoid formation of fruiting bodies during growth, $2 \%$ (w/v) casitone was added to the medium (Hansen \& Andreoli, I973). The bacteria, with the associated polysaccharide, were carefully removed from the agar surface and suspended in water containing $0.1 \%(\mathrm{v} / \mathrm{v})$ formalin solution. The material from four $13.5 \mathrm{~cm}$ plates was suspended in $15 \mathrm{ml}$ aqueous formalin. Bacteria were freed from polysaccharide by stirring in a vortex mixer at room temperature for up to $30 \mathrm{~min}$ and recovered by centrifugation. The process was repeated and the polysaccharide was precipitated from the pooled supernatant fluids with two volumes of cold $\left(-40^{\circ} \mathrm{C}\right)$ acetone. It was washed thoroughly with pure acetone, redissolved in a small volume of water, dialysed against distilled water overnight, reprecipitated with acetone, and dried under vacuum. The same method was 
used for separating bacteria and polysaccharides from the gelatinous deposits that adhered to the walls of flasks of liquid medium 4 to 5 days after inoculation with the strains E, A or M.

Polysaccharides synthesized in liquid cultures were also obtained by concentrating the culture fluids, either by lyophilization or in a rotary evaporator, to I/Ioth the original volume and precipitating with cold acetone. The products were much less pure (as judged by paper chromatography of their monosaccharide contents) than other preparations and were purified by digestion with ribonuclease or by the addition of protamine sulphate to remove RNA and pronase digestion to destroy protein. Finally the products were treated with an equal volume of $90 \%(\mathrm{w} / \mathrm{v})$ aqueous phenol at $60{ }^{\circ} \mathrm{C}$ for $5 \mathrm{~min}$, and the upper aqueous layer was recovered by low speed centrifugation at $0^{\circ} \mathrm{C}$, dialysed free of phenol and lyophilized.

Polysaccharides were also obtained from the fruiting bodies, which were carefully removed from the surface of the growth medium using a small platinum loop. All strains produced fruiting bodies after $\mathrm{I} 4$ days' incubation on cell agar at $30^{\circ} \mathrm{C}$. In strains $\mathrm{E}$ and $\mathrm{M}$ the conversion from bacilli to fruiting bodies was almost complete, but the other two strains showed a mixture of the two bacterial forms. Microcyst-containing fruiting bodies did not adhere to the medium surface and were readily removed by the pliable platinum loop. Bacillary forms and their associated polysaccharides adhered very strongly to the agar surface and could only be removed from it by very vigorous scraping with a stronger wire loop or scalpel. The material from twenty $13.5 \mathrm{~cm}$ plates of each strain was suspended in $4 \mathrm{ml}$ aqueous formalin and subjected to ultrasonication (MSE ultrasonicator at $20 \mathrm{kc} / \mathrm{s}$ nominal power) for I $5 \mathrm{~s}$. Cysts were separated by low-speed centrifugation, resuspended in water and again subjected to ultrasonic irradiation for $15 \mathrm{~s}$. The pooled supernatant fluids were used as the source of 'fruiting body polysaccharides' which were recovered by precipitation with cold acetone.

Analytical methods. All the micromethods used were sensitive in the range of 5 to $10 \mu \mathrm{g}$ monosaccharide. Total hexose, methyl pentose and pentose assays were performed on unhydrolysed material by the techniques of Sutherland \& Smith (1973). D-Glucose and D-galactose were determined using the appropriate oxidase-based procedures on material

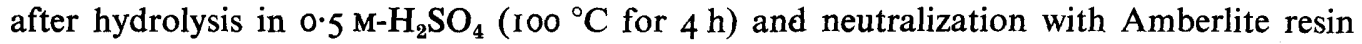
IR4 10 in the bicarbonate form. Total amino sugar was assayed in hydrolysates $(6 \mathrm{M}-\mathrm{HCl}$ at $100{ }^{\circ} \mathrm{C}$ for $6 \mathrm{~h}$ ) after evaporation of acid in vacuo. The same hydrolysates were used for specific assays of $\mathrm{D}$-galactosamine using the galactose-oxidase reagent.

The presence of monosaccharides in acid hydrolysates was examined by descending paper chromatography in butan-I-ol-pyridine-water $(6: 4: 3$, by vol.) (solvent A) or ethyl acetateacetic acid-pyridine-water $(5: 1: 5: 3$, by vol.) (solvent B). Paper electrophoresis in a Locarte instrument was performed in pyridinium acetate buffer (pyridine-acetic acid-water, I0:4:86, by vol.) $\mathrm{pH} 5 \cdot 3$, using Whatman $3 \mathrm{MM}$ paper.

Radioactive polysaccharide was prepared by the addition of uniformly ${ }^{14} \mathrm{C}$-labelled protein hydrolysate (Radiochemical Centre, Amersham, Buckinghamshire) to plates of cell agar or Cio medium ( $2 \mu \mathrm{Ci}$ in $20 \mathrm{ml}$ medium in $8 \mathrm{~cm}$ Petri dish) and harvesting as described above. After hydrolysis and paper chromatography to separate the monosaccharides, chromatograms were scanned in a 4 Pi scanner (Tracerlab, Weybridge, Surrey). Areas containing radioactivity were cut out from the chromatograms and counted in $0.5 \%(\mathrm{w} / \mathrm{v})$ PPO (2,5-diphenyloxazol) in toluene in a Packard Tricarb scintillation spectrometer. 
RESULTS

\section{Growth of Myxococcus strains}

On plates of Cro medium as described by Reichenbach \& Dworkin (1969), the strains used for this study sometimes produced fruiting bodies within two days. To avoid this and to ensure maximum polysaccharide production, the bacteria were routinely grown on agar containing $2 \%(\mathrm{w} / \mathrm{v})$ casitone (Hansen \& Andreoli, 1973) for 3 days before harvesting. The higher concentration of organic nitrogen in this variation of the medium apparently suppressed fruiting body formation. The entire growth was easily stripped from the surface of the medium using a large inoculating loop. No fruiting bodies were present and microscopic examination showed only filamentous bacteria and the absence of microcysts. In Cio liquid medium, up to 3 days' incubation also produced vegetative bacteria only. Prolonged incubation led to the accumulation of material on the sides of the flasks at the air-liquid interface. Examination of the deposits by the indian ink technique indicated that they contained a gelatinous matrix in which was embedded a mixture of bacilli and microcysts. The proportion of bacteria relative to microcysts was very variable. The deposits were sometimes brightly coloured, especially in preparations from strain $M$, but this pigmentation, too, varied greatly from one preparation to another.

The glycerol induction technique which proved so successful for the formation of microcysts in $M$. xanthus strain MFB (Dworkin \& Gibson, 1964) was ineffective with our strains, which failed to yield dispersed growth. Conversion of bacilli to microcysts rarely exceeded 50 to $70 \%$, even after prolonged incubation. An alternative technique for obtaining microcysts and their associated polysaccharides was used. Bacteria were grown on Klebsiella agar on large plates at $30^{\circ} \mathrm{C}$. The initial spreading growth appeared to contain little mucilaginous material, but adhered very strongly to the agar surface. The bacteria could only be removed from the medium with great difficulty. After I4 days' incubation, any residual vegetative cells still adhered strongly to the agar surface and were found only at the periphery of the Petri dishes. Most of the agar surface was now covered with brightly coloured fruiting bodies which were easily removed from the medium using an inoculating loop. Microscopic examination failed to reveal bacillary forms but showed masses of microcysts and their associated slime. The cysts were readily freed from slime by brief ultrasonic treatment followed by centrifugation. Polysaccharides from liquid and solid cultures and from fruiting bodies were prepared and their compositions compared with cell wall lipopolysaccharides.

\section{Polysaccharides from cultures on solid media}

The copious amounts of extracellular polysaccharide produced by the Myxococcus strains on solid media could easily be separated from the bacteria and precipitated with acetone. All strains yielded white fibrous precipitates of hygroscopic material with high carbohydrate content (as judged by the anthrone test). Portions of all four polymers were hydrolysed and subjected to paper chromatography in solvent A. All the hydrolysates contained mannose and glucose as the major monosaccharides. Galactose was found in all the polysaccharides except that from strain E, glucosamine was detected in the polysaccharides of strains $A$ and MFB, and galactosamine was only found in the material from strain A. The glucose and galactose were always present as the D-isomers, as they reacted with the respective oxidase reagents; the galactosamine was also identified as the $D$-isomer, being susceptible to oxidation with D-galactose oxidase. All four preparations were analysed for the sugars detected by paper chromatography (Table I). 
Table I. The composition of exopolysaccharides secreted by Myxococcus strains grown on solid medium

\begin{tabular}{|c|c|c|c|c|c|c|}
\hline \multirow[b]{2}{*}{ Strain } & \multirow{2}{*}{$\begin{array}{c}\text { Yield of } \\
\text { polysaccharide } \\
\text { (g/I00 g dry wt } \\
\text { bacteria) }\end{array}$} & \multirow[b]{2}{*}{$\begin{array}{c}\text { Sugars detected } \\
\text { chromatographically }\end{array}$} & \multicolumn{4}{|c|}{ Analysis $\dagger$} \\
\hline & & & Mannose & D-Glucose & $\begin{array}{c}\text { D- } \\
\text { Galactose }\end{array}$ & $\begin{array}{l}\text { Hexos- } \\
\text { amine }\end{array}$ \\
\hline $\mathbf{A}$ & $9 \cdot 2$ & Man, Glc, Gal, GlcN*, GalN & $16 \cdot 9$ & $36 \cdot 4$ & $18 \cdot 8$ & $1 \cdot 5$ \\
\hline $\mathbf{E}$ & $5 \cdot 7$ & Man, Glc & $22 \cdot 3$ & $5 I \cdot I$ & 0 & 0.8 \\
\hline $\mathbf{M}$ & $4 \cdot 5$ & Man, Glc, Gal, GlcN* & $18 \cdot 7$ & $25 \cdot 0$ & $3 I \cdot 2$ & $2 \cdot I$ \\
\hline MFB & 10.8 & Man, Glc, Gal, GlcN & $19 \cdot 8$ & $27 \cdot 7$ & $12 \cdot I$ & $14 \cdot 6$ \\
\hline
\end{tabular}

\section{Table 2. Monosaccharides detected in polysaccharides from cultures on radioactive medium}

Monosaccharides were first detected on a $4 \mathrm{Pi}$ scanner after separation by paper chromatography in solvent $\mathbf{A}$ and compared with known standards, located by staining with alkaline silver nitrate reagent. The spots corresponding to each sugar were then cut and the radioactivity determined in a counting fluid containing $0.5 \%(\mathrm{w} / \mathrm{v})$ PPO.

\begin{tabular}{|c|c|c|c|c|c|c|c|c|c|c|c|}
\hline \multirow[b]{2}{*}{ Strain } & \multicolumn{4}{|c|}{ Radioactivity (c.p.m.) } & \multicolumn{7}{|c|}{ Molar ratio } \\
\hline & $\underset{\text { GlcN* }^{*}}{\text { GlcNAc+ }}$ & Man & Glc & Gal & GlcN & : & Man & : & Glc & : & Gal \\
\hline $\mathbf{A}$ & 30 & I96I & 2597 & 1636 & - & : & $I \cdot 2$ & : & $I \cdot 6$ & : & $I \cdot O$ \\
\hline E & 0 & I I 54 & 2640 & 0 & 一 & : & $I \cdot O$ & : & $2 \cdot 3$ & : & 一 \\
\hline $\mathbf{M}$ & 3 & $86 r$ & 832 & $224 I$ & - & : & $I \cdot 0$ & : & $I \cdot 0$ & : & $2 \cdot 7$ \\
\hline MFB & 2320 & 2749 & 2423 & 1643 & $I \cdot 4$ & : & $I \cdot 7$ & : & 1.5 & : & $I \cdot O$ \\
\hline
\end{tabular}

* The areas corresponding to glucosamine and $\mathrm{N}$-acetylglucosamine were counted separately and the sum of the total counts (less background) recorded.

Although estimates of component monosaccharides were obtained using specific techniques, the value for mannose was derived as the difference between the total hexose value (cysteine- $\mathrm{H}_{2} \mathrm{SO}_{4}$ reaction) and the sum of the glucose and galactose contents. It was thus likely to be less accurate than the specific estimations with the oxidase reagents. Also, different hydrolysis conditions were required for the neutral sugar and the amino sugar determinations. To check the accuracy of these results, radioactive $\left({ }^{14} \mathrm{C}\right.$-labelled) polysaccharide was prepared, hydrolysed with $0.5 \mathrm{M}-\mathrm{H}_{2} \mathrm{SO}_{4}$ and separated into neutral and amino sugars electrophoretically. After chromatography in solvent $A$, the radioactivity associated with each sugar was determined (Table 2). A comparison of the quantities of monosaccharides determined by scintillation counting shows that they are in fairly good agreement with the values obtained by the specific assays. The radioactive measurements also act as a control against galactose derived from agar contaminating the bacterial polysaccharides. The trace amounts of amino sugars found in the unlabelled polysaccharide preparations of strains $\mathrm{A}, \mathrm{E}$ and $\mathrm{M}$ probably derived from contaminating lipopolysaccharide. The glucosamine in strain MFB is, however, clearly a constituent of the polysaccharide.

As ketal or acyl groups would not be revealed by the chromatographic procedures employed, the polymers were tested for the presence of pyruvate and acetate using micromodifications of the 2,4-dinitrophenylhydrazine and hydroxamic acid techniques respec- 
Table 3. Polysaccharides isolated from Myxococcus fruiting bodies

\begin{tabular}{|c|c|c|c|c|c|c|c|c|}
\hline \multirow[b]{2}{*}{ Strain } & \multirow[b]{2}{*}{ Yield* } & \multirow[b]{2}{*}{$\begin{array}{c}\text { Sugars detected } \\
\text { chromatographically }\end{array}$} & \multicolumn{6}{|c|}{ Analysis $\dagger$} \\
\hline & & & Acetate & $\begin{array}{l}\text { Man- } \\
\text { nose }\end{array}$ & Glucose & $\begin{array}{l}\text { Galact- } \\
\text { ose }\end{array}$ & $\begin{array}{l}\text { Glucos- } \\
\text { amine }\end{array}$ & $\begin{array}{l}\text { Galactos- } \\
\text { amine }\end{array}$ \\
\hline $\mathbf{A}$ & 一 & $\begin{array}{l}\text { Man, Glc, Gal, GlcN, } \\
\text { GalN }\end{array}$ & - & 3.0 & $30 \cdot 2$ & $13 \cdot 6$ & 8.8 & $8 \cdot 3$ \\
\hline $\mathbf{E}$ & $12 \cdot 8$ & $\begin{array}{l}\text { Man, Gle, traces of GlcN } \\
\text { and GalN }\end{array}$ & 1.8 & $24 \cdot 6$ & $5 I \cdot I$ & 0 & $4 \cdot 8$ & $2 \cdot 3$ \\
\hline $\mathbf{M}$ & $17 \cdot 1$ & $\begin{array}{l}\text { Man, Glc, Gal, GlcN, } \\
\text { trace of GalN }\end{array}$ & $I \cdot 3$ & $8 \cdot 7$ & $59 \cdot 6$ & $13 \cdot 6$ & $16 \cdot 0$ & $4 \cdot I$ \\
\hline MFB & $18 \cdot 3$ & $\begin{array}{l}\text { Man, Glc, Gal, traces of } \\
\text { GlcN and GalN }\end{array}$ & $1 \cdot 7$ & $18 \cdot 6$ & $32 \cdot 0$ & 12.5 & 6.8 & $3 \cdot 0$ \\
\hline
\end{tabular}

* As \% dry wt of fruiting bodies.

$\dagger$ As $\%$ dry wt of polysaccharide. Multiple estimations all fell within $10 \%$ of the average value.

$\$$ Composition as \% dry wt of polysaccharide.

Table 4. The composition of Myxococcus lipopolysaccharides

\begin{tabular}{|c|c|c|c|c|c|c|c|c|c|}
\hline \multirow[b]{2}{*}{ Strain } & \multirow{2}{*}{$\begin{array}{c}\text { Yield } \\
\text { (g/I00 g } \\
\text { dry wt } \\
\text { bacteria) }\end{array}$} & \multirow[b]{2}{*}{$\begin{array}{c}\text { Sugars detected } \\
\text { chromatographically }\end{array}$} & \multicolumn{7}{|c|}{ Monosaccharide contents ( $\%$ dry wt LPS) } \\
\hline & & & $\begin{array}{l}\text { Rham- } \\
\text { nose }\end{array}$ & Ribose & $\begin{array}{l}\text { Man- } \\
\text { nose }\end{array}$ & Glucose & $\begin{array}{l}\text { Galact- } \\
\text { ose }\end{array}$ & $\begin{array}{l}\text { Glucos- } \\
\text { amine }\end{array}$ & $\begin{array}{l}\text { Galactos- } \\
\text { amine }\end{array}$ \\
\hline $\mathbf{A}$ & $1 \cdot 70$ & $\begin{array}{l}\text { Rib, Glc, Gal, } \\
\text { GlcN, GalN }\end{array}$ & 一 & $6 \cdot I$ & - & $18 \cdot 5$ & $13 \cdot 0$ & $6 \cdot 3$ & 16.9 \\
\hline $\mathbf{E}$ & $1 \cdot 47$ & $\begin{array}{l}\text { Rha, Man, Glc, } \\
\text { Gal, GlcN, GalN }\end{array}$ & $12 \cdot 7$ & - & $26 \cdot 5$ & 14.4 & $16 \cdot 3$ & $10 \cdot 0$ & $4 \cdot 8$ \\
\hline $\mathbf{M}$ & 0.45 & $\begin{array}{l}\text { Rha, Man, Glc, } \\
\text { GlcN, GalN }\end{array}$ & $4 \cdot 8$ & 一 & $20 \cdot 6$ & $19 \cdot 9$ & $4 \cdot 3$ & $7 \cdot 8$ & $15 \cdot 6$ \\
\hline MFB & $0 \cdot 70$ & $\begin{array}{l}\text { Man, Glc, Gal, } \\
\text { GlcN, GalN }\end{array}$ & - & 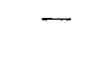 & $9 \cdot 7$ & $29 \cdot 4$ & $7 \cdot 2$ & $6 \cdot 5$ & I6.8 \\
\hline
\end{tabular}

tively. Pyruvate or similar ketals were definitely absent. The results for acetate were equivocal and poorly reproducible, but may indicate low acetyl contents of about $I$ to $3 \%$ in the polysaccharides. The turbidity of some of the polysaccharide solutions was a primary cause of the poor results obtained for this assay.

\section{Polysaccharides from liquid cultures}

Polysaccharides prepared from liquid cultures were initially much less pure than those from solid medium. A high extinction at $260 \mathrm{~nm}$, indicative of nucleic acid contamination, suggested that considerable lysis of the bacteria had occurred. Even after purification by treatment with ribonuclease and protamine sulphate, residual u.v.-absorbing material was present. The yields of purified polysaccharides ( $\mathrm{g}$ polysaccharide/I00 $\mathrm{g}$ dry wt bacteria) were similar to those obtained from cultures on solid medium, but as large amounts of material were lost during purification the initial yields from liquid media may have been higher. Hydrolysates of the polysaccharides revealed the same major monosaccharide components in approximately the same relative proportions as were found in the material from solid medium. In addition, the amino sugars glucosamine and galactosamine were present and, in the preparation from strain $\mathrm{E}$, small amounts of galactose. These sugars probably derive from contaminating lipopolysaccharide from the walls of lysed bacteria. 


\section{Fruiting body polysaccharides}

Of the four stains used in the present study, all except strain A yielded sufficient fruiting body material for accurate results to be obtained. The fruiting bodies were removed from the surface of plates of bacterial cell medium and microscopic examination showed them to be free from bacillary forms. Because of their large size, after the brief ultrasonic treatment the microcysts were easily sedimented by centrifugation and separated from the viscous polysaccharide solutions. The polysaccharides precipitated with acetone were all white powders, which indicated their freedom from the brightly-coloured microcysts. The yield of material from strain A was very low as it did not convert to fruiting bodies as readily as the other strains. The results presented for strain a consequently represent a single set of analyses on one polysaccharide preparation; for the others, duplicate analyses were made on at least three separate preparations (Table 3). Attempts to use ${ }^{14} \mathrm{C}$-labelled bacteria as the growth substrate yielded fruiting bodies and their components with low levels of radioactivity. Hydrolysis of the polysaccharides and measurement of radioactivity in the component sugars failed to give meaningful results.

\section{Lipopolysaccharides}

Lipopolysaccharides could only be extracted from the bacillary forms of the Myxococcus strains and were obtained in the aqueous phase after extraction with $90 \%(w / v)$ aqueous phenol. No material could be extracted from the microcysts by this technique into either the aqueous or the phenolic phase. Hydrolysis of complete microcysts followed by neutralization and paper chromatography in various solvents revealed several monosaccharides. They indicated that microcysts contain both mucopeptide (White et al. 1968) and some form of polysaccharide. No satisfactory method for extraction and purification of the microcyst polysaccharides has yet been found.

The lipopolysaccharides from the bacteria formed gelatinous deposits on ultracentrifugation in a manner similar to preparations from other Gram-negative bacteria. The yields, although variable, fell within the range noted for other genera and also for other species of Myxobacteria (Sutherland \& Smith, 1973). The cysteine-sulphuric acid test indicated that heptose was either absent or was present in quantities below the limits of detection. The thiobarbituric acid reaction used for detection of 2-keto-3-deoxyoctonic acid (KDO) was positive for all the preparations, but in the absence of suitable standards no quantitative estimations were performed.

The monosaccharides detected in lipopolysaccharide hydrolysates (Table 4) revealed strain differences. Rhamnose was found only in two preparations (strains $E$ and $M$ ), while ribose was a component of the lipopolysaccharides from strains $A$ and E. One polymer (strain A) lacked mannose and another (strain $M$ ) lacked galactose. No traces of $O$-methyl xylose were observed, although this monosaccharide was first identified in $M$. fulvus lipopolysaccharide preparations (Weckesser et al. 1971) and later reported in material from other myxobacterial strains (Sutherland \& Smith, I973).

\section{DISCUSSION}

The vegetative bacteria of the four strains of Myxococcus examined contain lipopolysaccharides extractable with aqueous phenol. These polymers resemble others previously examined from various Myxobacteria in their monosaccharide content, containing several neutral hexoses, methyl pentose and amino sugars, but lacking detectable amounts of 
heptose (Sutherland \& Smith, I973). They thus differ from the Enterobacteriaceae in which heptose is a major component of the core portion of the lipopolysaccharide (e.g. Nikaido, 1973), but resemble some other Gram-negative bacteria such as Xanthomonas campestris (Volk, 1966) and Rhodopseudomonas capsulata (Weckesser, Mayer \& Drews, 1970). Unlike M. fulvus (Weckesser et al. 197I ; Rosenfelder et al. 1974), our strains had no 3-O-methylD-xylose in their lipopolysaccharides. Clearly this unusual sugar is not present in all myxobacterial lipopolysaccharides.

Cell walls of $M$. xanthus have a total carbohydrate content of only 4.7 to $7.5 \%$ (w/w), and rhamnose, 'hexosamine', glucose and galactose are present in the cell wall hydrolysates (Mason \& Powelson, 1958). These monosaccharides probably derive from the lipopolysaccharide. The methods used in the present study did not yield any of the glucose-containing material bound to mucopeptide which was identified by Johnson \& White (1972) as a component of bacilli and to a lesser extent myxospores.

Although the association of exopolysaccharide and bacilli in cultures of Myxobacteria has frequently been recognized, the nature of the polysaccharides does not appear to have been examined. In Myxococcus virescens the production of anthrone-positive material was taken to indicate polysaccharide and was shown to occur mainly in the stationary phase of growth (Haskå \& Ståhl, 197I); some of the material was thought to be derived from cell autolysates rather than truly extracellular material. Several polysaccharide fractions have been prepared from $M$. xanthus (I. Pratt and D. J. Tipper, unpublished work) and found to contain glucose, galactose and $\mathrm{N}$-acetylglucosamine in varying proportions. This is in fairly good agreement with the observation that the exopolysaccharides associated with the bacillary forms of Myxococcus species are neutral polymers lacking the uronic acids so commonly found in bacterial exopolysaccharides (Sutherland, 1972). The hexose components were predominantly mannose and glucose, although other monosaccharides were present in some preparations and some may have been derived from cell wall polymers released by autolysis. Similar extracellular polymers have been identified in cultures of Rhizobium species (Clapp \& Davis, 1970) and Pseudomonas aeruginosa (Brown, Foster \& Clamp, 1969). The yields of myxobacterial polymers were relatively high. The role of these slime polymers is still unknown (Dworkin, 1973); the absence of free carboxyl groups indicates that it cannot be the binding of ions or other nutrients.

The lack of appreciable differences in composition between the normal exopolysaccharides and those associated with the microcysts in the fruiting bodies was unexpected. The small amounts of galactosamine detected in the preparations from strain MFB appear insufficient to account for the observations of White et al. (1968), and this amino sugar probably forms part of a polymer contained in the microcysts rather than the polysaccharide matrix surrounding them. The system is also noticeably different from that occurring in the cellular slime mould Dictyostelium discoideum which forms a polysaccharide (containing galactose) specifically associated with the spore capsules (Loomis \& Sussman, 1966). In other Gramnegative bacteria, the polysaccharides found in cell walls and extracellularly often contain markedly different sugars (Sutherland, 1972) and thus permit distinct regulatory mechanisms for precursor formation. Such polymers are, however, generally formed under conditions of carbohydrate and energy excess. Fruiting body formation in the genus Myxococcus is normally a result of nutrient limitation (Dworkin, 1973) and it might be expected from the teleological sense that the bacteria would use pre-existing polysaccharide precursors during fruiting body formation rather than start to synthesize new types of nucleoside diphosphate sugars. It is not clear from the present work whether all the exopolysaccharide found in fruiting bodies is produced de novo following initiation of encystment, or whether any of 
this material is derived from pre-existing polymer, located either in the cell walls or extracellularly.

The authors are indebted to Mrs E. Chalmers for technical assistance and to Professor D. J. Tipper for providing his unpublished results.

\section{REFERENCES}

Brown, M. R. W., Foster, J. H. S. \& Clamp, J. R. (1969). Composition of Pseudomonas aeruginosa slime. Biochemical Journal 112, $521-525$.

Clapp, C. E. \& DAvis, R. J. (I970). Properties of extracellular polysaccharides from Rhizobium. Soil Biology and Biochemistry 2, 109-117.

Dworkin, M. (1972). The Myxobacteria: new directions in studies of procaryotic development. Critical Reviews in Microbiology I, 435-452.

Dworkin, M. (1973). Cell-cell interactions in the Myxobacteria. Symposia of the Society for General Microbiology 23, $125-142$.

DwORKIN, M. \& GIBSON, S. M. (1964). A system for studying microbial morphogenesis: rapid formation of microcysts in Myxococcus xanthus. Science, New York 146, 243-244.

HANSEN, C. W. \& ANDREOLI, A. J. (1973). Some aspects of amino acid metabolism in the fruiting Myxobacterium, Myxococcus xanthus. Archiv für Mikrobiologie 92, I-I0.

HASKÅ, G. \& STÅHL, S. (197I). Variants of Myxococcus virescens exhibiting dispersed growth. Physiologia plantarum 24, I36-142.

Johnson, J. L. \& Chilton, W. S. (1966). Galactosamine glycan of Chondrococcus columnaris. Science, New York 152, 1247.

Johnson, R. Y. \& WHITE, D. (1972). Myxospore formation in Myxococcus xanthus: chemical changes in the cell wall during cellular morphogenesis. Journal of Bacteriology 112, 849-855.

Loomis, W. F. \& Sussman, M. (1966). Commitment to the synthesis of a specific enzyme during cellular slime mould development. Journal of Molecular Biology 22, 40I-404.

Mason, D. J. \& Powelson, D. (1958). The cell wall of Myxococcus xanthus. Biochimica et biophysica acta 29, I-7.

NiKaIDO, H. (1973). Biosynthesis and assembly of lipopolysaccharides and the outer membrane layer of Gram-negative cell wall. In Bacterial Membranes and Walls, pp. 131-208. Edited by L. Leive. New York: M. Dekker.

ReichendaCh, H. \& Dworkin, M. (1969). Studies on Stigmatella aurantiaca (Myxobacterales). Journal of General Microbiology 58, 3-14.

RoSENFELDER, G., LÜDERITZ, O. \& WeSTPHAL, O. (1974). Composition of lipopolysaccharides from Myxococcus fulvus and other fruiting and non-fruiting Myxobacteria. European Journal of Biochemistry 44, $41 \mathrm{I}-\mathbf{4} 20$.

Sutherland, I. W. (1972). Bacterial exopolysaccharides. Advances in Microbial Physiology 8, 143-213.

SUTHERLAND, I. W. \& SMITH, M. L. (1973). The lipopolysaccharides of fruiting and non-fruiting Myxobacteria. Journal of General Microbiology 74, 259-266.

VoLK, W. (1966). Cell wall lipopolysaccharides from Xanthomonas species. Journal of Bacteriology 91, 39-42.

WeCKESSER, J., MAYER, H. \& Drews, G. (1970). The identification of 3- $O$-methyl-L-rhamnose (L-acofriose) as a constituent of the lipopolysaccharides of Myxococcus fulvus and Rhodopseudomonas viridis respectively. European Journal of Biochemistry I6, I53-163.

WeCKesser, J., Rosenfelder, G., MAYeR, H. \& LÜDeritz, O. (1971). The identification of 3-O-methyl-Dxylose and 3-O-methyl-L-lyxose as constituents of the lipopolysaccharides of Myxococcus fulvus and Rhodopseudomonas viridis respectively. European Journal of Biochemistry 24, I $12-1$ I 5.

White, D., Dworkin, M. \& TIPPER, D. J. (1968). Peptidoglycan of Myxococcus xanthus: structure and relation to morphogenesis. Journal of Bacteriology 95, 21 86-2 197. 